\title{
Primary tuberculosis of the thyroid gland: a case report
}

\author{
Sant Parkash Kataria, Parul Tanwar*, Sneh Singh, Sanjay Kumar
}

Department of Pathology, Post Graduate Institute of Medical Sciences, Rohtak, Haryana-124001, India

\section{ARTICLE INFO}

Article history:

Received 15 March 2012

Received in revised form 27 March 2011

Accepted 28 April 2012

Available online 28 October 2012

\section{Keywords:}

Tuberculosis

Thyroid

Granuloma

\begin{abstract}
Tuberculosis of the thyroid gland is an uncommon disease and primary involvement of thyroid is even more rare. It is a rare disease even in countries in which tuberculosis is endemic. The diagnosis is often difficult as the clinical presentation has no distinct characteristics. Clinical course of the disease may resemble toxic goiter or acute thyroiditis or may follow a subacute or chronic growth pattern without specific symptomatology. Histologically presence of necrotizing epithelioid cell granulomas along with langhans type giant cells are the hallmark of thyroid tuberculosis. Demonstration of acid fast bacilli by ZN staining confirms the diagnosis, but this stain is frequently negative in tissue sections.
\end{abstract}

\section{Introduction}

Thyroid gland is rarely affected by tuberculosis. It was once considered immune from the disease till Lebert in 1862 reported the involvement of the gland in a patient with disseminated tuberculosis[ [1]. Tuberculosis of thyroid is rare even in countries with high prevalence of tuberculosis[2]. There have been isolated case reports and few case series of thyroid tuberculosis in the literature[3]. The supposed reasons for the relative immunity of thyroid gland from tuberculosis are the bactericidal attribute of the colloid, extensive vascularity and high iodine content of the gland[2] the primary form of the disease is even rarer. Most of the cases are accompanied by other loci of the disease in the body. Sometimes associated with regional lymph nodes, thyroid tuberculosis can mask a thyroid tumor, which poses diagnostic and therapeutic issues.[4]. Thyroid involvement can be symptom free as seen in generalized miliary spread, diffuse or localized swelling of the gland[5]. It can also present as thyroid abcess in pulmonary tuberculosis patients[6]. We present a case of a 35 years old female who presented with painless solitary thyroid nodule for one year, which on histology was proved to be tuberculosis of thyroid.

\footnotetext{
* Corresponding author: Dr. Parul Tanwar, Department of Pathology Post Graduate, Institute of Medical Sciences, Rohtak - 124001, Haryana, India.

Tel: 09896437937

E-mail: drparultanwar@gmail.com
}

\section{Case history}

A 35 years old female presented with swelling front of neck ( right side ) for one year. The swelling was slowly progressing in size since last 6 months, the same duration from which the patient complained of hoarseness of voice. There was no complaint of dysphagia or dyspnea. The patient did not give any history of fever, weight loss, cough or hemoptysis. There was no past or family history of tuberculosis On examination there was a firm swelling $4.5 \mathrm{~cm} \times 3 \mathrm{~cm}$ in size, moving with deglutition. The swelling was non tender and did not show any signs of inflammation. Thyroid profile of the patient revealed normal levels of the thyroid hormones. Ultrasonography of the neck revealed a nodular lesion involving most of the right lobe of thyroid which was heterogenous in echogenicity-showing hypoechoic areas along with areas of microcalcification. A partial thyroidectomy was performed. On gross examination the right lobe of thyroid was enlarged measuring $5 \mathrm{~cm} \times 2 \mathrm{~cm}$ $\times 1 \mathrm{~cm}$. Cut section showed multiple cystic areas filled with colloid along with a focus of caseous necrosis. Microscopically the characteristic features of multinodular goitre with adenomatous change showing areas of caseation necrosis (Figure 1), epithelioid cell granulomas and langhans type giant cells (Figure 2). Ziehl Neelsen staining for acid fast bacilli using 20\% sulfuric acid showed numerous acid fast bacilli conforming to the morphology of mycobacteria(Figure 3) 


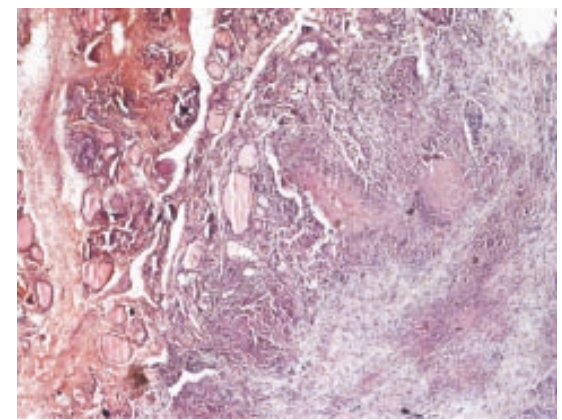

Figure 1. Photomicrograph showing caseating granuloma along with surrounding thyroid follicles (H \& E, 40X).

\section{Discussion}

It is observed that certain tissues are relatively resistant to tuberculosis, tuberculosis of heart, striated muscles, thyroid and pancreas are rarely encountered[]]. Tuberculosis of thyroid gland whether primary or secondary is an extremely rare disease. According to literature its frequency is $0.1 \%-0.4 \%$ in histologically diagnosed specimens[3]. In a study conducted by Das et al the incidence of tuberculous thyroiditis was $0.6 \%$ among 1283 thyroid lesions subjected to aspiration cytology[8]. Rokitansky found only 21 cases of thyroid tuberculosis out of 20758 surgically resected thyroid glands $(0.1 \%)^{[7]}$. The ability of thyroid to resist infection is attributed to a number of factors-prosperous lymphatic and vascular supply, well developed capsule and high iodine content of the gland[6], Colloid possessing bactericidal action, destruction of tubercle bacilli due to increased physiological activity of phagocytes in hyperthyroidism and possible antitubercular role of thyroid hormones[5].

Symptoms of thyroid tuberculosis are non specific and variable[6]. The patient may be asymptomatic or have symptoms of dysphonia, dysphagia, dysponea and rarely recurrent laryngeal nerve paralysis due to expanding gland[3]. The pathology of thyroid gland may be as follows: a)Multiple lesions throughout the gland like miliary TB; b)Enlargement of gland due to caseating granulomas; c)Cold abcess formation sometimes with multiple sinuses; d)Chronic fibrosing tuberculosis, difficult to distinguish from De Quervein's thyroiditis; e)Acute abcess formation, when there is a danger of making wrong diagnosis of carcinoma[7]. The characteristic morphological features of tuberculous inflammation are necrotizing epithelioid cell granulomas with langhans type giant cells. Demonstration of acid fast bacilli by ZN staining confirms the diagnosis, but this stain is often negative in tissue sections[3] Microscopically four morphological variations of tuberculous thyroiditis have been distinguished: 1)Multiple tubercles in case of miliary TB; 2)Solitary and sometimes merging tubercles; 3)Foci of caseous necrosis or cold abcess, and 4)Cicatrised tubercle foci[5].

Seed in 1939 described three criteria for diagnosis of thyroid tuberculosis-1)Demonstration of acid fast bacilli within thyroid; 2)A necrotic or abcessed gland and 3) Demonstration of tuberculous focus outside. Histological and bacteriological confirmation is adequate to make diagnosis and fulfilment of third criteria is not essential[5] Grossly tuberculosis of thyroid gland is difficult to distinguish from other inflammations of the thyroid as well as from carcinoma thyroid[2]. On histology as well many diseases may cause granulomatous inflammation of thyroid like granulomatous thyroiditis, fungal infection, tuberculosis, sarcoidosis, granulomatous vasculitis and foreign body reaction. However caseating necrosis is seen only in tuberculous inflammation[9].

Tuberculosis of thyroid, although a rare entity should be kept in mind as a differential diagnosis when evaluating a thyroid nodule or abcess. Final diagnosis is made on histopathological examination.

\section{Conflict of interest statement}

We declare that we have no conflict of interest.

\section{References}

[1] Khan NA, Patgaroo AR, Murtaza SW, Kotwal S, Singh P, Chowdhry ND. Isolated tuberculosis of thyroid gland. JK Sci 2002; 4: 87-88.

[2] Zivaljevic V, Paunovic I, Diklic A. Tuberculosis of thyroid gland: A case report. Acta Chir Belg 2007; 107: 70-72.

[3] Abdulsalam F, Abdulaziz S, Mallik AA. Primary tuberculosis of the thyroid gland. Kuwait Med J 2005; 37: 116-118.

[4] Rakotoarisoa AHN, Riel AM, Rakoto FA, Randriatahina PG, Razafimandimby T, Razafindrakoto HR, et al. Tuberculosis of the thyroid gland: A report of two cases. Fr ORL 2007; 92: 318-320.

[5] Gupta KB, Gupta R, Varma M. Tuberculosis of the thyroid gland. Pulmon 2008; 9: 65-68.

[6] Mpikashe P, Sathekge MM, Mokgoro NP, Ogunbanjo GA. Tuberculosis of the thyroid gland: a case report: case study. South Afr Fam Pract 2004; 46: 19-20.

[7] Pandit AA, Joshi AS, Ogale SB, Sheode JH. Tuberculosis of thyroid gland. Indian J Tub 1997; 44: 205-207.

[8] Das DK, Pant CS, Chachra KL, Gupta AK. Fine needle aspiration cytology of tuberculous thyroiditis. A report of eight cases. Acta Cytol 1992; 36: 517-522.

[9] Maitra A. The endocrine system. In: Kumar V, Abbas AK, Fausto N, Aster JC, editors. Robbins and cotran pathological basis of disease, 8th ed. Philadelphia: Elsevier; 2010, p. 1097-1164. 